\title{
Determinants of Malnutrition Among Ever-married Women in Bangladesh
}

\author{
Md. Abdus Salam Akanda ${ }^{1 *}$, Most. Sonia Khatun ${ }^{2}$ and A H M Musfiqur Rahman Nabeen ${ }^{2}$ \\ ${ }^{1}$ Department of Statistics, Dhaka University, Dhaka-1000, Bangladesh \\ ${ }^{2}$ Department of Statistics, Pabna University of Science and Technology, Pabna-6600, Bangladesh
}

(Received: 4 December 2019; Accepted: 24 February 2021)

\begin{abstract}
Underweight and overweight problems have serious consequences on the health status of women in Bangladesh. The objective of this study is to find the important factors that may influence a woman for being underweight, overweight and obese. Multinomial logistic regression model is fitted for this purpose. The stepwise variable selection procedure is used to select covariates for the model. Information of ever-married 15,323 non-pregnant women is extracted from Bangladesh Demographic and Health Survey, 2014 data. Seven covariates (region, living place, wealth index, respondent's marital status, current working status, education, and current age) are selected finally for the model from the initially considered thirteen variables. The results of the study demonstrate that the women living in Sylhet region, rural area, widowed or divorced, having less education and younger age are more likely to become underweight. Conversely, the women are living in Khulna region, urban area, married, not working, having more than 10 years of schooling and age 35-49 are at higher risk of experiencing overweight or obesity. Thus, the Government of Bangladesh should take proper initiatives to improve underweight and overweight problem of women considering the findings of this study.
\end{abstract}

Keywords: Malnutrition, body mass index, multinomial logistic regression, odds ratio, Bangladesh

\section{Introduction}

Bangladesh is facing many socio-economic, epidemiologic and demographic challenges over the last decades. Although it is a highly populated country, its total population is increasing every year. The extra people that are added every subsequent year create some additional problems including economic inequality, child and maternal mortality, unplanned urbanization, originating diseases, changing disease pattern, food crisis and adulteration, spread of non-communicable diseases etc. ${ }^{1-3}$ To cope with these problems people are changing their traditional life style. Consequently, the nutritional status has also been changing. ${ }^{2}$

Underweight problem is very common in Bangladesh but the prevalence rate of overweight is increasing every year. ${ }^{4-}$ 6 According to the Bangladesh Demographic and Health Survey (BDHS), 2004 prevalence rate of underweight among Bangladeshi women was $34.2 \%$ and it decreases to $18.3 \%$ in $2014 .^{7-8}$ Undoubtedly it is an important indication of the improvement in health status. However, the number of overweight women has increased during the mentioned period. In 2004, the percentage of overweight ever-married adult women was $9.8 \%$ but within 10 years it has become more than double $(20.5 \%)$ in $2014 .^{7-8}$ Thus, the coexistence of underweight and overweight/obese has become a public health concern in Bangladesh. Due to the underweight problem women may experience increased mortality and morbidity, loss of productivity, pregnancy complications, giving birth of underweight children etc. ${ }^{9-10}$ Simultaneously, obesity and overweight are accountable for coronary heart disease, diabetes, dementia, chronic illness, high blood pressure, musculoskeletal disorders etc. ${ }^{11-13}$

It is well-established that urbanization, sedentary life style, economic advancement, over spread of social media, playing computer games, reduction of physical activity, transformation of transportation system etc. may cause overweight problem. ${ }^{14-18}$ On the other hand, underweight problem is common due to the prevalence of poverty and illiteracy. ${ }^{4-5}$ Nonetheless, further investigations are needed to know what other socioeconomic, geographic and demographic factors that are mainly responsible for the under and over nutrition in Bangladesh. Thus, the main aim of this study is to find out the important factors that are associated with underweight, overweight and obesity among adult women in Bangladesh.

\section{Data and Methods}

\section{Data}

This study is conducted based on the most recent Bangladesh Demographic and Health Survey (BDHS), 2014 data. The survey was conducted by NIPORT under the Ministry of Health and Family Welfare (MOHFW). A two-stage stratified random sampling procedure was followed. At the first stage, the survey randomly selected 600 enumeration areas (EAs) (among them 393 in rural areas and 207 in urban areas) applying probability proportional to the EA size. A complete household listing operation was then carried out in all of the selected EAs to provide a sampling frame for the second-stage selection of households. At the second stage, a systematic random sample of 30 households was selected on average from each EA. There are three types of questionnaire in BDHS, 2014: Woman's, Household, and Community Questionnaire. The data used for this study is extracted from Woman's questionnaire. For understanding the changing pattern of nutritional status among ever-married women over the period 2004-2014; BDHS 2004, 2007 and 2011 data are used. Similar sampling design was applied for all of the surveys. The BDHS reports can provide more details about the survey designs.

\section{Measure of outcome variable}

Body mass index (BMI), a key indicator of nutritional status of women is used as an outcome variable. BMI can 
be obtained through dividing an individual's weight (Kg.) by the square of height $\left(\mathrm{m}^{2}\right)$ of that individual. This study defined four categories of the outcome: underweight (BMI $\left.<18.5 \mathrm{~kg} / \mathrm{m}^{2}\right)$, normal weight $\left(18.5\right.$ to $\left.24.9 \mathrm{~kg} / \mathrm{m}^{2}\right)$, overweight (25 to $29.9 \mathrm{~kg} / \mathrm{m}^{2}$ ) and obese (BMI>30 $\left.\mathrm{kg} / \mathrm{m}^{2}\right)^{19}$.

\section{Covariates}

Based on literature review, ${ }^{4-5,9-10,12,20}$ region (Sylhet, Rangpur, Rajshahi, Khulna, Dhaka, Chittagong, Barisal), living place (urban, rural), watching TV (not watching, less than once/ week, at least once/ week), wealth index (richest, richer, middle, poorer, poorest), contraceptive method (modern method, traditional, no method), marital status (widowed/Other, married), current working status of respondent (yes, no), respondent's education $(10+, 6-10,0-$ 5 , none), number of household member (4 or less, greater than 4), current age (35-49, 25-34, 15-24), individual's age at first birth (18 or less, 18+), partner's education level (10+, 6-10, 0-5, none) and NGO membership of respondent (yes, no) are considered as the covariates for this study.

\section{Methods}

\section{Multinomial logistic regression model}

Multinomial logistic regression model is applied to find out the effects of the selected covariates on BMI of women as it has four categories. Any of the categories can be considered as the reference category of this model. ${ }^{21}$ In this study, "normal weight" is treated as the reference category. Suppose that there are $J$ categories in the outcome variable. Let, $Y_{i} ; i=1,2, \ldots, n$ be the outcome obtained from the $i^{t h}$ individual and $x_{i}=\left(x_{i 1}, \ldots, x_{i k}, \ldots, x_{i K}\right)$ be the $(K \times$ 1) vector of covariates associated with the response $Y_{i}$. Also, let $\beta_{j}=\left(\beta_{1 j}, \ldots, \beta_{k j}, \ldots, \beta_{K j}\right)$ be the $(K \times 1)$ vector of regression parameters, where $j=2,3, \ldots, J$. Then, the multinomial logistic regression model can be defined as

$$
\operatorname{logit}\left(\pi_{j}\right)=\log \left(\frac{\pi_{j}}{\pi_{1}}\right)=x_{i}^{\prime} \beta, \text { for } j=2,3, \ldots, J
$$

where $\pi_{j}=\frac{\exp \left(x_{i}^{\prime} \beta_{j}\right)}{1+\exp \left(x_{i}^{\prime} \beta_{j}\right)}$. The odds ratio of the $\mathrm{j}^{\text {th }}$ category for the covariate $x_{k}$ can be calculated using the expression $\exp \left(\beta_{k j}\right)$.

\section{Method of variable selection}

There are two conflicting objectives of fitting a regression model. Firstly, the model should include as many regressors as possible for the prediction purpose of the outcome variable. On the other hand, the model should include as few regressors as possible because the variance of the prediction increases as the number of regressors increases. ${ }^{22}$ Thus, it is needed to tradeoff between these two concepts and to select the 'best' model.

\section{(a) Stepwise regression method}

Stepwise variable selection method is the combination of forward selection and backward elimination method. In this method at each step all regressors entered into the model previously are reassessed again that is a regressor added at an earlier step may be redundant at later step because of the relationship between the earlier regressor and the later one. ${ }^{23}$ The procedure is explained in the following subsection with an example on the basis of Bayesian Information Criteria (BIC).

At the first step, a regression model has to be fitted without any covariates and should be used to calculate the value of BIC.

$$
Y \sim 1, \quad\left(B I C=B I C_{\text {null }}\right)
$$

All covariates should be included one by one in the equation $(i)$ and fitted $P$ (total number of covariates) number of regression models. Then, the value of BIC for each model is calculated. The value of BIC should be kept in an ascending order and have to choose the model with minimum value of BIC. Suppose, for the covariate $X_{2}$, BIC is minimum. Then a new model with only one variable $X_{2}$ has to be fitted as

$$
Y \sim \beta_{2} X_{2}, \quad\left(B I C=B I C_{\text {new original }}\right)
$$

After this stage, the concern is not only the inclusion of a new covariate but also exclusion of the previously entered covariate $\left(X_{2}\right)$. Suppose $X_{1}$ is added to the new original model (ii), and BIC becomes minimum compared to add other covariate or exclude the previous variable $\left(X_{2}\right)$. Then, $X_{1}$ should include to 'new original' model (ii). The process should be repeated to add or remove another covariate. Finally, this procedure will stop and will select a model when no covariate can be added or removed.

\section{(b) Bayesian information criteria (BIC)}

The Bayesian Information Criterion (BIC) was introduced by Schwarz (1978). ${ }^{24}$ Let $K$ be the number of parameters in the model, $n$ be the number of observations and $\log L_{K}$ be the maximized numerical value of the log-likelihood. Then,

$B I C=-2 \log L_{K}+K \log (n)$.

Akaike Information criteria (AIC) ${ }^{25}$ can also be used in this case. Mathematically, $A I C=-2 \log L_{K}+2 K$. But for $n>8$ the penalty in BIC $[K \log (n)]$ will be greater than AIC $[2 K]$. As the penalty term is larger in BIC, it chooses smaller model. Therefore, in this study BIC is used rather than AIC to select the covariates.

\section{Results}

The analysis of this study is conducted mainly in four steps: changing pattern of BMI, univariate, bivariate, and multivariate analysis. The results are presented in the following subsections.

\section{(a) Changing pattern of BMI}

The patterns of women being normal, underweight, overweight and obese over the period 2004-14 are given in Fig.1. It demonstrates that the percentages of normal weight women remain almost same over the last 10 years. 
However, there are significant fluctuations in underweight and overweight. In 2004, the percentage of underweight women was $34.2 \%$, but in 2014 it decreases to $18.3 \%$. The figure shows increasing pattern for overweight and obese. For instance, compared to 2004, the percentage of overweight women has become more than double and obesity has become more than triple in 2014.

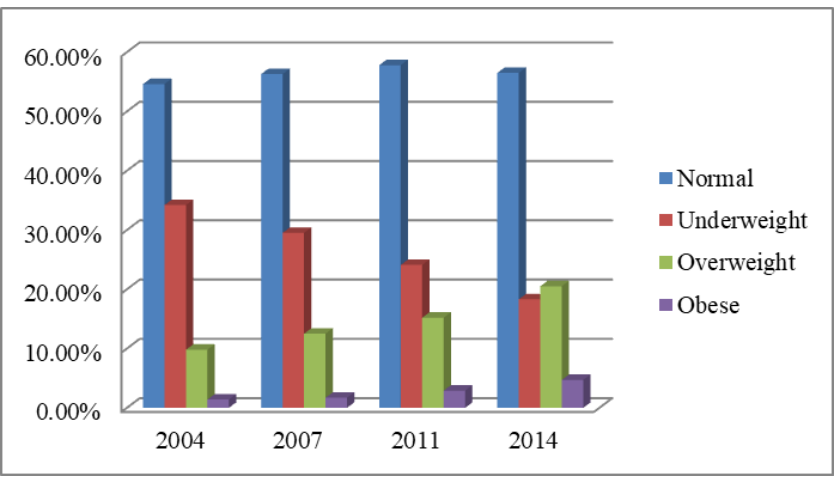

Fig. 1. Changing patterns of normal, underweight, overweight and obesity percentages for the ever-married women aged 15-49 years over the period 2004-2014

\section{(b) Univariate analysis}

The percentage distribution of the selected characteristics according to the Bangladesh Demographic and Health Survey, 2014 data is presented in Table 1. The largest percent of respondents are from Dhaka division (17.3\%) and the lowest respondents are from Sylhet division $(11.3 \%)$. It shows that most of the respondents are from rural areas $(65.7 \%)$ compared to the urban areas $(34.3 \%)$. About $40.2 \%$ women do not watch TV, $8.8 \%$ watch TV less than once per week and $51 \%$ watch TV at least once per week. Among all women about $21.3 \%$ are from richest, $21 \%$ from richer, $20.2 \%$ from middle, $19 \%$ from poorer and $18.5 \%$ from poorest family. Most of the women $(56.8 \%)$ use modern contraceptive method and $8.8 \%$ use the traditional method whereas $35.1 \%$ do not use any contraceptive method. It is found that $94.1 \%$ women are currently married and $5.9 \%$ are widowed/others. More than half of the women are not currently working $(66.7 \%)$. Besides, $25.6 \%$ women are illiterate and only $6.8 \%$ women have more than ten years of schooling. It is found that most of the women $(57.7 \%)$ are from families with greater than four members. The percentage of women aged 15 to 24 years is $22.5 \%$ and aged 35 to 49 years is $39.9 \%$. Large numbers of women $(64.7 \%)$ give their first birth before reaching 18 years. The distribution of the education level of the partners of the respondent is no education (30.4\%), primary education (27.8\%), secondary education (29\%) and having education more than 10 years $(12.8 \%)$. A large number of women $(73.6 \%)$ aren't related with NGO whereas $26.6 \%$ are associated with NGO.

\section{(c) Bivariate Analysis}

To carry out bivariate association between a specific covariate and the outcome variable, Chi-square test is performed. It is observed that all the covariates show significant relationship with nutritional status (BMI) at $1 \%$ level of significance.

The distribution of different covariates according to the normal, underweight, overweight and obesity are displayed in Table 1. It shows that the prevalence of underweight is the highest in Sylhet region $(29.4 \%)$ whereas it is the lowest in the Khulna region (13\%). On the other hand, in case of overweight, the prevalence is lowest in Sylhet region (14\%) and the highest in the Khulna region $(24.2 \%)$. In general, the prevalence of underweight is higher in rural areas $(21.5 \%)$ while it is lower in urban areas $(12.2 \%)$, but the prevalence of overweight is lower in rural areas (16.2\%) and higher in urban areas $(28.9 \%)$. The prevalence of overweight is $27.4 \%$ for the women who watch TV for at least once a week. The prevalence rate of overweight and obesity is increasing with the increase of the wealth status whereas the rate is decreasing for underweight. For instance, the prevalence rate of overweight is the highest in the richest group (37.7\%) and for underweight it is the lowest in the richest group $(6.3 \%)$. While the underweight rate is lower among the married women $(17.8 \%)$, the prevalence of overweight is greater among them $(20.9 \%)$. The prevalence of overweight is higher among the nonworking women $(21.4 \%)$ compared to the working women $(18.7 \%)$. The pattern of prevalence rate for the respondent's education is same as wealth index for both overweight and underweight. For example, the prevalence rate of underweight is the largest in the group of women who do not have any formal education $(24.5 \%)$ but the prevalence of obese is the smallest among them $(2.7 \%)$. In the case of current age, it is observed that the prevalence rate of overweight and obese are increasing with the increase of age, however, the prevalence rate of underweight for the women age group 15-24 (26.9\%) is higher compared to the age group 35-49 (16.4\%).

\section{(d) Factors of underweight, overweight and obese}

The main objective of this study is to find the important factors of nutritional status (BMI). For this purpose, seven covariates (region, living place, wealth index, marital status, working status, education and current age) are selected applying the stepwise variable selection method. Then the multinomial logistic regression is fitted considering these seven covariates. The adjusted and unadjusted odds ratio (OR) for underweight, overweight and obese compared to normal weight for the selected variables are given in Table 3. 
Table 1. Percentage distribution and $p$-values of $\chi^{2}$ test of nutritional condition (BMI) of women according to different selected covariates

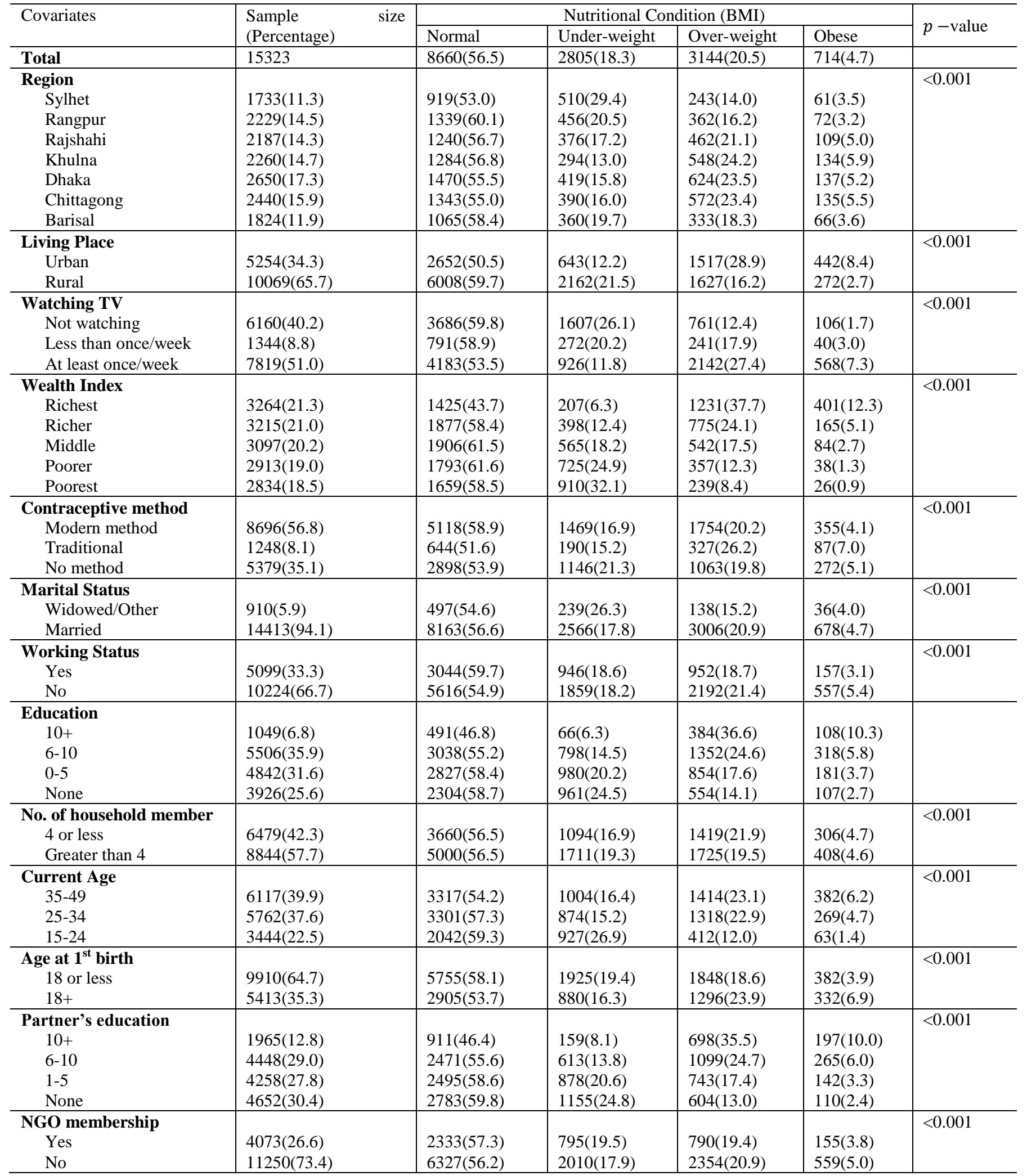


Table 2. Adjusted and unadjusted OR with $95 \%$ confidence interval for the selected covariates obtained from multinomial logistic regression

\begin{tabular}{|c|c|c|c|c|c|c|}
\hline \multirow[t]{2}{*}{ Characteristics } & \multicolumn{2}{|c|}{ Underweight $(n=2805)$} & \multicolumn{2}{|c|}{ Overweight $(n=3144)$} & \multicolumn{2}{|c|}{ Obese $(n=714)$} \\
\hline & Adjusted OR & Unadjusted OR & Adjusted OR & Unadjusted OR & Adjusted OR & Unadjusted OR \\
\hline $\begin{array}{l}\text { Living Place } \\
\quad \text { Rural (RC) } \\
\text { Urban } \\
\end{array}$ & $0.93(0.83,1.04)$ & $0.67(0.61,0.74)$ & $1.33(1.20,1.46)$ & $2.11(1.94,2.97)$ & $1.73(1.44,2.07)$ & $3.68(3.14,4.31)$ \\
\hline $\begin{array}{l}\text { Wealth Index } \\
\text { Richest (RC) } \\
\text { Richer } \\
\text { Middle } \\
\text { Poorer } \\
\text { Poorest } \\
\end{array}$ & $\begin{array}{l}1.39(1.15,1.69) \\
1.91(1.58,2.31) \\
2.50(2.06,3.04) \\
3.20(2.63,3.89) \\
\end{array}$ & $\begin{array}{l}1.46(1.21,1.75) \\
2.04(1.72,2.43) \\
2.78(2.35,3.29) \\
3.78(3.19,4.46) \\
\end{array}$ & $\begin{array}{l}0.56(0.49,0.63) \\
0.41(0.36,0.48) \\
0.32(0.27,0.37) \\
0.24(0.20,0.30) \\
\end{array}$ & $\begin{array}{l}0.48(0.43,0.54) \\
0.33(0.29,0.37) \\
0.23(0.20,0.26) \\
0.17(0.14,0.19) \\
\end{array}$ & $\begin{array}{l}0.39(0.32,0.49) \\
0.22(0.17,0.29) \\
0.12(0.08,0.17) \\
0.09(0.06,0.15) \\
\end{array}$ & $\begin{array}{l}0.31(0.26,0.38) \\
0.16(0.12,0.20) \\
0.08(0.05,0.11) \\
0.05(0.03,0.08) \\
\end{array}$ \\
\hline $\begin{array}{l}\text { Working Status } \\
\text { Yes (RC) } \\
\text { No } \\
\end{array}$ & $1.05(0.96,1.16)$ & $1.06(0.97,1.16)$ & $1.16(1.06,1.28)$ & $1.25(1.14,1.36)$ & $1.70(1.40,2.06)$ & $1.92(1.60,2.30)$ \\
\hline $\begin{array}{l}\text { Education } \\
10+(\mathrm{RC}) \\
6-10 \\
0-5 \\
\text { None } \\
\end{array}$ & $\begin{array}{l}1.28(0.97,1.70) \\
1.50(1.13,2.00) \\
1.78(1.33,2.38) \\
\end{array}$ & $\begin{array}{l}1.95(1.49,2.55) \\
2.58(1.96,3.36) \\
3.10(2.37,4.05) \\
\end{array}$ & $\begin{array}{l}0.92(0.79,1.09) \\
0.75(0.63,0.89) \\
0.61(0.50,0.73) \\
\end{array}$ & $\begin{array}{l}0.56(0.49,0.66) \\
0.38(0.33,0.45) \\
0.31(0.26,0.36) \\
\end{array}$ & $\begin{array}{l}0.95(0.74,1.23) \\
0.82(0.62,1.10) \\
0.64(0.46,0.89) \\
\end{array}$ & $\begin{array}{l}0.47(0.38,0.60) \\
0.29(0.23,0.38) \\
0.21(0.16,0.28) \\
\end{array}$ \\
\hline $\begin{array}{c}\text { Current Age } \\
35-49 \text { (RC) } \\
25-34 \\
15-24 \\
\end{array}$ & $\begin{array}{l}0.96(0.86,1.07) \\
1.84(1.62,2.08)\end{array}$ & $\begin{array}{l}0.87(0.79,0.97) \\
1.50(1.35,1.67)\end{array}$ & $\begin{array}{l}0.83(0.76,0.92) \\
0.38(0.33,0.44)\end{array}$ & $\begin{array}{l}0.93(0.86,1.02) \\
0.47(0.41,0.53)\end{array}$ & $\begin{array}{l}0.64(0.54,0.77) \\
0.21(0.16,0.28)\end{array}$ & $\begin{array}{l}0.70(0.61,0.83) \\
0.27(0.21,0.35)\end{array}$ \\
\hline
\end{tabular}

$R C$ : Reference category; Normal weight $(n=8660)$ is used as reference

It is observed that the women from Rangpur, Rajshahi, Khulna, Dhaka, Chittagong and Barisal division are less likely to be underweight and more likely to be overweight/obese compared to Sylhet division. The adjusted OR shows that living place is not an important factor for underweight problem although the unadjusted OR indicates its significance. In addition, the urban women are $33 \%$ more likely to be overweight and $73 \%$ more likely to be obese relative to rural women. The risk of being underweight increases with the reduction of wealth status while the risk of being overweight and obesity increase with the increase of wealth status. For example, the women from the poorest family are $220 \%$ more likely to be underweight than the richest family, on the other hand, women from the poorest family are $76 \%$ and $91 \%$ less likely to be overweight and obese, respectively than the richest family. The married women are $38 \%$ less likely to be underweight, $41 \%$ more likely to be overweight and $36 \%$ more likely to be obese compared to widowed/other women. The current working status is not a significant factor for underweight but the women who are not currently working are $70 \%$ more likely to be obese than the working women. Respondent's education is negatively associated with underweight and positively associated with overweight and obese. The non-educated women are $78 \%$ more likely to be underweight compared to women who have more than 10 years of education. On the contrary, the non-educated women are $36 \%$ less likely to experience obesity compared to women having more than 10 years of education. It is also found that younger women are more likely to be underweight but less likely to be overweight or obese. The women of current age 15-24 years are $84 \%$ more likely to be underweight, $62 \%$ less likely to be overweight and $79 \%$ less likely to be obese compared to the women of current age 35- 49 years.

\section{Discussion}

In Bangladesh, the problem regarding underweight was very common. Before resolving the underweight problem, the incidence of overweight among women is becoming frequent. ${ }^{6,10,16-17}$ Thus, underweight and overweight are creating public health hazard simultaneously. ${ }^{12-10}$ Over the period 2004-2014, there exists an overall downward trend of being underweight and an upward trend of being overweight. At present, the prevalence of overweight is higher than underweight among women in Bangladesh. 
The findings of this study show that urban women are more likely to be overweight compared to rural women. This is analogous to other previous research. ${ }^{5}$ The results also reveal that Sylhet division is more likely to experience underweight problem whereas Rajshahi, Khulna, Chittagong region are at higher risk of overweight compared to Sylhet region. This finding highlights that urbanized areas are at increased risk of overweight and the agriculture-based areas are at more risk of underweight. Even though Dhaka is the most urbanized region of Bangladesh, the severe relocation of rural poor people may lessen its effect on overweight. Previous studies shows that for less education and lower wealth index, the risk of underweight is higher but the threat of overweight is lower. ${ }^{10}$ This current study found a similar inverse relationship of nutritional status with respondent's education and wealth index. This is because the women from the poorest families are struggling to fulfill their daily required calories whereas the richest women are taking foods of high calories, nonetheless doing no physical work usually. The life style is furthermore responsible for overweight problem. In the upper wealth index group, there exists much use of cars and motor vehicles, less walking, lower physical activity and preference of fast food which are exposures of overweight. On the other hand, the prevalence of underweight among the poor or illiterate women is due to not having enough income or due to lack of awareness. In contrast, the higher educated women are more exposed to overweight because of their life style or even due to lack of awareness. It is found that married and non-working women are at higher risk of being overweight or obese. The younger women are more likely to be underweight whereas the older women are at increased risk of overweight.

This study has some limitations. It is difficult to find a unique 'best' model for the model selection. Some researchers might be dubious about the use of BIC in case of cross-sectional data. In this study, BMI is considered as the only index of nutritional status although there may exist other indices. Only the pregnant women are excluded from the sample size although the women who have been given birth a child currently may have some influence on BMI.

\section{Conclusion and Policy Implication}

This study shows that underweight and overweight problem simultaneously exist in Bangladesh. Hence before taking any public health interventions the dual existence of the two malnutrition problems should be taken into consideration. Some key recommendations are made on the basis of this study to address underweight and overweight problems among ever-married women in Bangladesh. These are:

(i) The government of Bangladesh should take necessary steps to reduce underweight problem in Sylhet region. In this regard, industrialization and poverty reduction are required for the area. In Khulna region, some interventions are needed to decrease the overweight problem. (ii) Though underweight problem exists in both urban and rural areas, the overweight problem is acute in urban areas. Thus, special interventions like opening of walking space, increase of consciousness about the bad effect of fast food, less physical activity are needed in urban areas.

(iii) Government should provide some medical support, subsidized nutritious food, employment opportunities to reduce under-nutrition among the poor rural women.

(iv) Awareness is needed among the group of higher educated and wealthier women to reduce overweight problem.

(v) Dietary education should be started from early years of life.

\section{Acknowledgement}

The authors are grateful to the authority of NIPORT, Bangladesh for the open access of BDHS, 2014, 2011, 2007, 2004 survey data. They are grateful to the Department of Statistics, University of Dhaka for allowing them to use their logistic support. They are also very grateful to referee for his careful reading of the manuscript and several helpful suggestions that considerably improved the presentation.

\section{References}

1. Streatfield, P.K. and Z.A. Karar, 2008. Population challenges for Bangladesh in the coming decades. Journal of health, population, and nutrition, 26(3), 261.

2. Karar, Z.A., N. Alam and P.K. Streatfield, 2009. Epidemiological transition in rural Bangladesh, 1986-2006. Global Health Action, 2.

3. Nabeen, A. H. M. M. R. and M. A. S. Akanda, 2018. Association between economic inequality and under-five child malnutrition: Evidence from Bangladesh Demographic and Health Survey. Dhaka University Journal of Science, 66(1), 73-78.

4. Khan M.N., M.N.I. Mondol, M.R. Islam, M.A. Al-Mamun and M. Shitan, 2015. Trends in body mass index and its determinants among ever-married non-pregnant women in Bangladesh. Mal J Nutr., 21(2), 191-205.

5. Kamal, S.M., C.H. Hassan and G.M. Alam, 2015. Dual burden of underweight and overweight among women in Bangladesh: patterns, prevalence, and socio demographic correlates. J Health Popul Nutr., 33(1), 92-105.

6. Mendez, M.A., C.A. Monteiro and B.M. Popkin, 2005. Overweight exceeds underweight among women in most developing countries. Am J Clin Nutr., 81(3), 714-21.

7. Bangladesh Demographic and Health Survey 2004, 2005. National Institute of Population Research and Training (NIPORT), Dhaka, Bangladesh; Mitra and Associates, Dhaka, Bangladesh; and ICF International, Calverton, Maryland USA.

8. Bangladesh Demographic and Health Survey 2014, 2011 and 2007. National Institute of Population Research and Training (NIPORT), Dhaka, Bangladesh; Mitra and Associates, 
Dhaka, Bangladesh; and ICF International, Rockville, Maryland USA.

9. Nube, M.and G.J Van Den Boom, 2003. Gender and adult undernutrition in developing countries. Annals of Human Biology, 30(5), 520-537.

10. Biswas, T., S.P. Garnett, S.Pervin and L.B.Rawal, 2017. The prevalence of underweight, overweight and obesity in Bangladeshi adults: Data from a national survey. PLOS ONE, 12(5), e0177395.

11. Gersh B.J., K. Sliwa, B.M.Mayosi and S Yusuf, 2010. Novel therapeutic concepts: the epidemic of cardiovascular disease in the developing world: global implications. European Heart Journal, 31(6), 642-48.

12. Ng, M., T. Fleming T and M. Robinson, et al., 2014. Global, regional, and national prevalence of overweight and obesity in children and adults during 1980-2013: a systematic analysis for the Global Burden of Disease Study 2013. The Lancet, 384(9945), 766-781.

13. Bishwajit, G., 2015. Nutrition transition in South Asia: the emergence of non-communicable chronic diseases. F1000Res, 4(8), doi: 10.12688/f1000research.5732.2.

14. Popkin, B.M., 2003. The nutrition transition in the developing world. Dev Policy Rev, 21(5-6), 581-97.

15. Sisson, S.B., M. Krampe, K. Anundson and S. Castle, 2016. Obesity prevention and obesogenic behavior interventions in child care: a systematic review. Prev Med., 87, 57-69.

16. Sikorski, C., M. Luppa and S. Weyerer et al., 2014. Obesity and associated lifestyle in a large sample of multi-morbid German primary care attendees. PLoS One, 9(7), e102587.
17. Ghose, B., 2017. Frequency of TV viewing and prevalence of overweight and obesity among adult women in Bangladesh: a cross-sectional study. BMJ Open, 7, e014399.

18. Veitcha, J., G. Abbotta, A.T. Kaczynski, and et al., 2016. Park availability and physical activity, TV time, and overweight and obesity among women: findings from Australia and the United States. Health Place, 38, 96-102.

19. WHO Expert Consultation, 2004. Appropriate body-mass index for Asian populations and its implications for policy and intervention strategies. Lancet, 363, 157-63.

20. Ly K.A., T.G.N. Ton, Q.V. Ngo, T.T Vo and A.L. Fitzpatrick, 2013. Double burden: a cross-sectional survey assessing factors associated with underweight and overweight status in Danang, Vietnam. BMC Public Health, 13(35), https://doi.org/10.1186/1471-2458-13-35.

21. Agresti A., 1996. An Introduction to Categorical Data Analysis. University of Florida, John Wiley \& Sons, Inc.

22. Montogomery, D.C., E.A. Peck and G.G. Vining, 2012. Introduction to Linear Regression Analysis, $5^{\text {th }}$ edition. John Wiley \& Sons, Inc.

23. Draper, N. R. and H. Smith, 1998. Applied regression analysis. John Wiley \&Sons, Inc.

24. Schwarz, G., 1978. Estimating the dimension of a model. Annals of Statistics, 6, 461-464.

25. Akaike, H., 1973. Information theory and an extension of the maximum likelihood principle. In Petrov, B.N.; Csáki, F., 2nd International Symposium on Information Theory, Tsahkadsor, Armenia, USSR, September 2-8, 1971, Budapest:Akademiai Kiado. 267-281. 
